\title{
Quantitative Measures of Corrosion and Prevention: Application to Corrosion in Agriculture
}

\author{
J. C. SChOuteN*; P. J. Gellings*
}

The corrosion protection factor (c.p.f.) and the corrosion condition (c.c.) are simple instruments for the study and evaluation of the contribution and efficiency of several methods of corrosion prevention and control. The application of c.p.f. and c.c. to corrosion and prevention in agriculture in The Netherlands is considered in detail. Attention is paid to relations between c.p.f. and c.c., the corrosion costs, possible cost savings and the applied corrosion protection scheme on farms. It is shown that the c.p.f. and the c.c. are useful expedients in a preliminary analysis of corrosion costs and possible cost savings on farms in relation to the corrosion protection methods applied.

It is concluded that significant cost savings on arable farms can be derived by improving corrosion protection. No statistically significant cost savings are possible by improving corrosion protection on the dairy farms considered in this research.

\section{Introduction}

In a previous article, ${ }^{1}$ two quantitative valid measures of corrosion and corrosion prevention were proposed.

First, the corrosion protection factor (c.p.f.) was defined as a measure of the way and the extent that corrosion prevention and control were carried out in a concern, industry or farming activity. With help of the maintenance factor (m.f.) defined as a measure of the way and extent that inspection and preventative maintenance are applied, it was shown that the c.p.f. can be considered as a valid measure. The calculation procedure, some specific properties and examples of application in two farming activities in The Netherlands were shown.

Secondly, the corrosion condition of machinery and equipment (c.c.) was introduced and further defined as the technical external corrosion situation of the machine and/or its parts. The c.c. was established by using a simple classification schedule that could be applied by arranging all machines in an industry or sector under the respective conditions (indicated with numbers) according to their corrosion damage.

It was shown that the c.p.f. and the c.c. are simple instruments for the study and evaluation of the contribution and efficiency of several methods of corrosion prevention and control. C.p.f. can be correlated using statistical techniques with the corrosion costs and the corrosion condition of machinery and equipment with the purpose of analysing and improving the corrosion protection policy.

In this article the application of c.p.f. and c.c. to corrosion and its prevention in two types of farming are considered in detail. Attention is paid to connections between c.p.f. and c.c., the corrosion costs, possible cost savings and the applied corrosion protection scheme on the farms. The definitions and the calculation procedures of c.p.f. and c.c. are given in Appendix A which is based on the previous article. ${ }^{1}$

First, some general aspects of corrosion in agriculture are outlined in the following two sections.

* Laboratory for Inorganic Chemistry, Department of Chemical Technology, Twente University of Technology, P.O. Box 217, 7500 AE Enschede, The Netherlands

Received 8 March 1985; accepted in revised form 26 April 1986 


\section{Corrosion in agriculture: some technical aspects}

The wide variety of machinery, equipment, implements, fittings and buildings for farming purposes makes it difficult to define precisely and concisely where corrosion can be most damaging in agriculture. The situation is further complicated by the different types of environment, the "local microclimate", the type of farming activity, the compounds and chemicals used, the seasonal use of certain equipment and machinery and the applied methods of maintenance and corrosion protection. ${ }^{2-7}$

Generally, corrosion in agricultural environments can be very severe. For example, observations in animal buildings made it clear that corrosion there is at least comparable with that in a severe city atmosphere or the atmosphere in chemical industrics. ${ }^{6}$ In various farming activities all sorts of corrosive chemical compounds are widely used. These include fertilizers, chemicals for pest, disease and weed control (herbicides and pesticides), grain and silage preservatives, salts and weak acids, sterilizing chemical solutions for cleaning purposes, and solutions containing sulphates and chlorides. Also farming products, such as manure, farm wastes, grass juices, silage and slurries can be very aggressive.

The degradation of metals used for agricultural machinery and equipment, as a consequence of corrosion, generally takes a variety of forms: general corrosion, pitting, corrosion fatigue, stress corrosion cracking, etc. These forms have already been studied extensively in an industrial context; ${ }^{8,9}$ but they are also likely to be found in all their variety in agriculture. ${ }^{2,4,5,7}$ The corrosive attack of agricultural environments on machines leads to damage and a variety of defects. Also agricultural buildings and their fittings are vulnerable to corrosion. Animal houses especially, experience very severe corrosion attack due to the atmosphere which contains ammonia, weak acids, sulphur compounds, salts and moisture in high concentrations.

A comprehensive series of measures and methods for corrosion prevention and control in agriculture are given in the literature. ${ }^{2-4,8,9}$ They vary from good design, application of inorganic or metallic coatings and paints, cathodic protection, use of galvanized steel, stainless steel or corrosion resistant metals, to regular cleaning after use and good storage of machinery, application (after drying) of oil or greases, use of temporary protectives, short term inhibiting oils, lubricants and sealants. Insufficient corrosion protection will lead to the degradation of metals that finally results in various technical problems with economic consequences.

\section{Corrosion in agriculture: economic losses}

The economic corrosion losses can be divided into two cost groups: direct and indirect costs.

The direct corrosion costs are all costs that result as a direct consequence of corrosion, such as the use of better materials, painting, metallic coating, cathodic protection, and the costs of maintenance, repairs and replacements due to corrosion.

The indirect costs arising from corrosion include depreciation losses, loss of availability of equipment, yield losses, etc. When the depreciation period of the machinery is reduced, due to the needed earlier replacement caused by corrosion, the depreciation increases as may be illustrated from the following example. A piece of equipment costing $£ 600$ has a depreciation period of 3 years when good corrosion protection is applied. However, due to inferior corrosion protection this period is reduced to 2 years. Consequently, the depreciation per year increases from $£ 200$ to $£ 300$, and the depreciation loss is then $£ 100$ per year. This loss is assumed to arise as an indirect consequence of corrosion and is therefore included in the indirect corrosion costs. The costs of maintenance, repairs and replacements of small parts due to corrosion may differ in both situations. They are considered to be directly caused by 
corrosion and are therefore included in the direct corrosion costs. This classification of corrosion costs is generally applied in literature. ${ }^{10}$

In the United States of America, agriculture sustained ${ }^{10}$ in 1975 a $£ 1170 \mathrm{~m}$ direct loss due to metallic corrosion. Of this, $58 \%$ could have been saved by using known protection schemes. When indirect costs were considered the total corrosion loss figure rose to $£ 2943 \mathrm{~m}$, with $49 \%$ avoidable. The agricultural corrosion costs in the American findings were estimated to be $0.5 \%$ of the total cost of corrosion; however, the contribution to the avoidable costs amounted to $12.5 \%$. A survey of economic and technological aspects of corrosion in the agricultural industry, 5 in the United Kingdom (1980) revealed annual direct corrosion and materials degradation losses of about $£ 180 \mathrm{~m}$. The inclusion of approximate estimates for the indirect costs suggests that total annual corrosion losses could amount to morc than $£ 500 \mathrm{~m}$. In Sweden (1981) it was estimated ${ }^{6}$ that rusting of materials cost Swedish pig farmers at least 15 million Swedish Crowns per year unnecessarily (approximately $£ 1.5 \mathrm{~m}$ in 1981).

Theoretical comparison between the Dutch and English agricultural industries revealed that the annual direct corrosion costs in The Netherlands are approximately 420 million Dutch guilders $(\mathrm{fl} .420 \mathrm{~m})$ in farming activities, excluding horticulture. The indirect corrosion costs amount to about $\mathrm{fl} .830 \mathrm{~m}$, that is two-thirds of the total corrosion costs which are estimated to be more than fl. $1200 \mathrm{~m}$ annually. The direct corrosion costs in the dairy farming sector was estimated to be $f .110 \mathrm{~m}$ annually and in the arable farming activity $1.112 .0 \mathrm{~m}$ per year, which are respectively $46 \%$ and $27 \%$ of the total direct costs in the agricultural industries in The Netherlands ${ }^{6,11}$ (fl.100 $=\mathfrak{£} 21.62$ in 1980).

From these figures it can be concluded that the cost of corrosion to the agricultural industry is important and merits extensive investigation. In 1983 such an investigation was carried out in The Netherlands with four main aims as outlined in the following section.

\section{Aims and approach of the investigation}

The aims were respectively:

(a) to discover the technical causes and consequences of corrosion of agricultural means, such as machinery, equipment, installations and buildings;

(b) to establish an estimate of the resulting direct and indirect corrosion costs on the farms;

(c) to denote measures of corrosion control in order to prevent corrosion in this area;

(d) to propose organizational measures which are necessary to realize an improvement of corrosion prevention in Dutch agriculture.

In relation to the aims (b) and (c) the corrosion protection factor (c.p.f.) and the corrosion condition (c.c.) have been used.

The research programme consisted of an investigation on 11 arable and 11 dairy farms in the "Noord-Oost Polder" in The Netherlands and included an agricultural economic investigation that was performed at the Tax and Accountant Advice Office, where the bookkeeping and accountancy data of the farms were available and a technical investigation of corrosion for which the data were obtained with the help of an inquiry and a visit to the farms.

The object of the investigation at the Book-keeping Office was to collect economic, financial and possibly corrosion technical data in order to estimate the costs of corrosion of machinery, equipment and buildings and establish relevant corrosion technical information.

The cost data were gathered using the accounts for maintenance, repairs, replacements and small materials, the fiscal and business economic profit and loss accounts and the fiscal balance.

Only those expenses for maintenance, etc. were included that were connected with corrosion as the main cause. The distinction between maintenance costs due to corrosion 
and those due to other causes was established after having consulted the farmer. It will be clear that it is an important point to be able to make this distinction because usually more than one damage mechanism can operate simultaneously. However, in general, the farmer or his personnel were able to point clearly at corrosion if that was the main cause. In this way were fixed the costs of material and parts used for maintenance, repairs, and replacements as a result of corrosion and the labour costs (wages, etc.) due to corrosion related maintenance and repairs (e.g. performed at a garage).

Not included in this way were the labour costs of the maintenance and repair work carried out by the farmer, the personnel or co-operating members of the family. These are costs but generally not expenses. On the dairy farms this was justified because most of the dairy farmers did not carry out maintenance and repair works themselves. In most cases they were continuously employed the whole year with productive work and therefore not interested or able to carry out maintenance. So, this was done off-farm. In contrast, on the arable farms much maintenance and repair work was carried out by the farmer and his personnel. However, this was predominantly done in "slack time" when the farm workers were not continuously employed in productive farm work (e.g. during winter time). The cost of the labour time, therefore, was borne by the farmer, whether or not they were undertaking this maintenance work (if they did not do the maintenance work, and there was no other work to do, they might well be idle).

In this way the reduction in the earning capacity of the farmer or his family is also not taken into account (they could be doing something else that might be more profitable). Also not included were the costs of corrosion related repairs, maintenance and labour that the payee worker passes on to the farmer in his accounts.

The object of the inqiury and the farm visits was, among other things, to establish how far and to what extent specific corrosion prevention methods are applied and maintenance is carried out; to establish how far delay appears as a result of corrosion, and how large the indirect losses are (such as yield and process losses, waste of products, etc.); to establish how prominent a role corrosion plays in the replacement policy, and how large the possible depreciation losses are; and to make a survey of the corrosion condition of the machines, implements and buildings.

The direct and indirect costs, c.p.f., m.f. and c.c. were calculated with the data gathered in this way. The connections and correlations between these data were obtained with statistical and quantitative comparative economic methods. Some results are outlined in the following sections. Only the arable and dairy farming industries are considered.

\section{Results}

\subsection{Relation between c.p.f. and the corrosion costs}

Insight into the corrosion protection policy can be deduced by correlating c.p.f. and the corrosion costs. A survey of the average c.p.f. and corrosion costs in both farming activities is given in Table 1.

A few remarks can be derived from Table 1. The c.p.f. on arable farms is greater than on dairy farms. The direct corrosion costs amount to two-thirds of the total corrosion costs in both farming activities. The direct corrosion costs amount to about $2 \%$ of the total revenues in arable and dairy farming. In both farming activities the direct corrosion costs amount to $43 \%$ of the total costs for maintenance, repairs and small materials. The results of the correlation of c.p.f. and the direct corrosion costs (d.c.c.) are shown in Table 2.

The results in Table 2 show that a significant, positive connection exists on dairy farms between c.p.f. and the direct corrosion costs (d.c.c.) as a percentage of maintenance, repairs and small materials $(t=2 \cdot 12)$. This relation does not exist on arable farms $(t=0 \cdot 12)$. The direct corrosion costs in the dairy farming activity thus are more strongly influenced by the 
Table 1

Survey of the average c.p.f. and corrosion costs in the arable and dairy farming activities in The Noord-Oost Polder in The Netherlands in 1980 ( $\mathbf{1 . 1 0 0}=\$ 21.62$ in 1980)

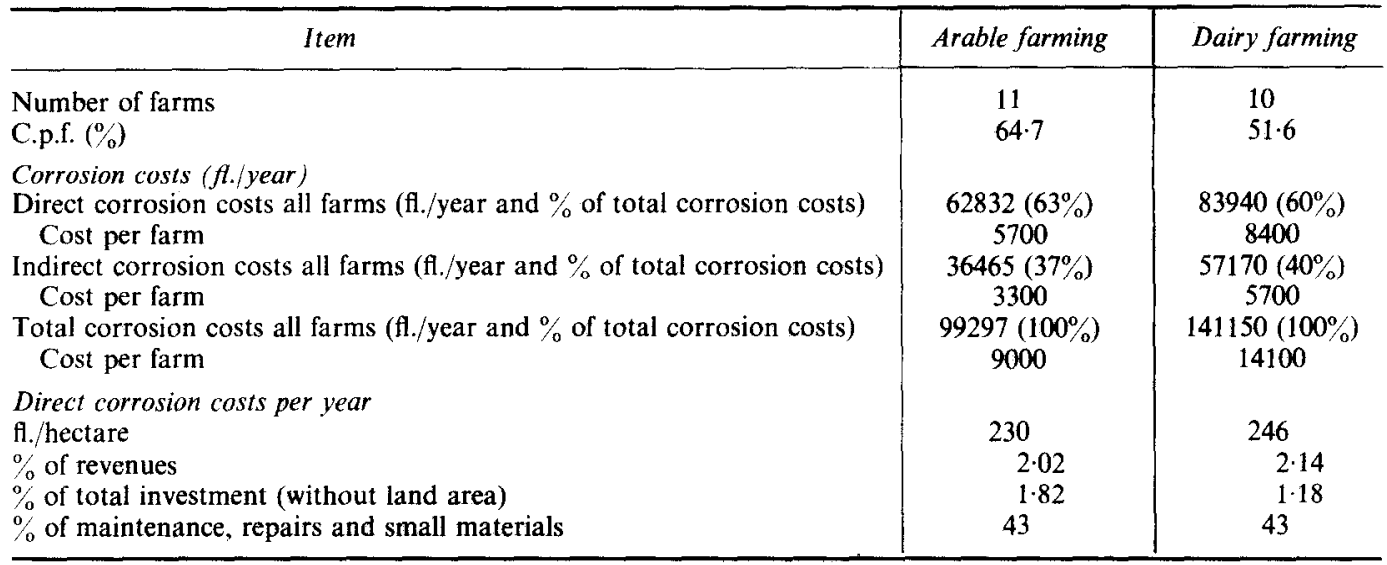

Table 2

Survey of the correlation between c.p.f. (\%) and the direct corrosion costs per year in both farming industries

\begin{tabular}{|c|c|c|c|c|c|c|}
\hline \multirow[b]{2}{*}{ Direct corrosion costs per year } & \multicolumn{3}{|c|}{ Arable farming } & \multicolumn{3}{|c|}{ Dairy farming } \\
\hline & $R$ & $t$ & $P$ & $R$ & $t$ & $P$ \\
\hline $\begin{array}{l}\text { f. hectare } \\
\% \text { of revenues } \\
\% \text { of total investment } \\
\text { (without land area) } \\
\% \text { of maintenance, repairs and } \\
\text { small materials }\end{array}$ & $\begin{array}{l}-0.31 \\
-0.16 \\
-0.23 \\
-0.004\end{array}$ & $\begin{array}{l}0 \cdot 98 \\
0 \cdot 49 \\
0 \cdot 71 \\
0 \cdot 12\end{array}$ & $\begin{array}{l}\text { n.s. } \\
\text { n.s. } \\
\text { n.s. } \\
\text { n.s. }\end{array}$ & $\begin{array}{l}-0.17 \\
-0.11 \\
-0.08 \\
+0.60\end{array}$ & $\begin{array}{l}0 \cdot 49 \\
0 \cdot 31 \\
0 \cdot 23 \\
\\
2 \cdot 12\end{array}$ & $\begin{array}{l}\text { n.s. } \\
\text { n.s. } \\
\text { n.s. } \\
<0.05\end{array}$ \\
\hline
\end{tabular}

$R$ : correlation coefficient

$t$ : value of $t$-test

$P$ : level of significance

n.s.: not significant, $P>0 \cdot 10$

extent and the way of carrying out repairs, replacements and maintenance than in arable farming. Correlation of c.p.f. and d.c.c. leads in all cases to $R<0$. The relations in these cases are not significant: $t<1.37(t=1.37$ corresponds to a level of significance $P=0 \cdot 10$, which is accepted here as a criterion).

\subsection{Relation between d.c.c. and separate protection methods}

In the previous section it was stated that the connection between c.p.f. and d.c.c. is not significant for a level $P<0 \cdot 10$. This is possibly a result of the fact that c.p.f. is composed of contributions of several methods of corrosion protection.

Specific protection methods can show a significant connection with a decrease of d.c.c., while other methods demonstrate no relation. This is explained with reference to a situation in which an increase of the application of a specific method already being used to a great extent, will only influence d.c.c. to a small extent. But this method still gives a great contribution to the total applied corrosion protection. 
An increase in the application of a method being used only to a small extent, can on the contrary contribute to a significant decrease of d.c.c. Correlation of c.p.f. (as a measuring instrument for the total applied corrosion protection) and d.c.c. in this way gives an incomplete picture. It is therefore necessary to obtain information about the connection between, on the one hand, the contribution of the separate protection methods to the total corrosion protection (in per cent of c.p.f.), and on the other, the direct corrosion costs. In this way it is possible to make a well-founded statement about the relation between the use of corrosion protection methods and a change in the direct corrosion costs.

In Table 3 a survey is given of the results of the correlation between (a) the contribu'ion of the separate methods ( $X_{1}$ to $\left.X_{5}\right)$ to c.p.f. per farm (in per cent of c.p.f.), and (b) the airect corrosion costs (measured as a percentage of the revenues).

The methods $X_{1}$ to $X_{5}$ are described in Appendix A; they can be outlined as: $X_{1}=$ use of oils and lubricants on metallic parts; $X_{2}=$ painting; $X_{3}=$ cleaning and washing; $X_{4}=$ cleaning with high pressure jet; $X_{5}=$ dry storage of machinery.

The summary in Table 3 gives rise to the following statements. Using lubricants and spraying with gasoline on corrosion sensitive parts (method $X_{1}$ ) and dry storing of machinery and equipment (method $X_{5}$ ) give on arable farms the greatest contributions, respectively $31 \%$ and $35 \%$, to the total applied corrosion protection. On dairy farms the greatest contributions are given by cleaning and washing of machinery (method $X_{3}$ and $X_{4}$ : $29 \%$ ) and dry storage (method $X_{5}: 44 \%$ ). Painting of rusty parts and surfaces (method $X_{2}$ ) delivers the smallest contribution to c.p.f.: in both industries only $8 \%$.

Painting of machinery and equipment shows in both industries a significant correlation (arable: $t=1.73$; dairy: $t=1.91$ ) with a decrease of d.c.c. Since painting as corrosion protection method is still used only to a small extent in comparison with other methods $(8 \%$ of c.p.f.), extension of use of the method gives an effective reduction of corrosion costs.

Dry storage (method $X_{5}$ ) shows on arable farms no clear trend directed towards a decrease of d.c.c.. The relation is not significant for $P<0 \cdot 10$. Also no connection exists on

Table 3

Correlation between (a) the contribution of the separate methods $X_{1}$ to $X_{5}$ to c.p.f. per farm (in per cent of c.p.f.), and (b) the direct corrosion costs per year (percentage of the revenues), on arable and dairy farms

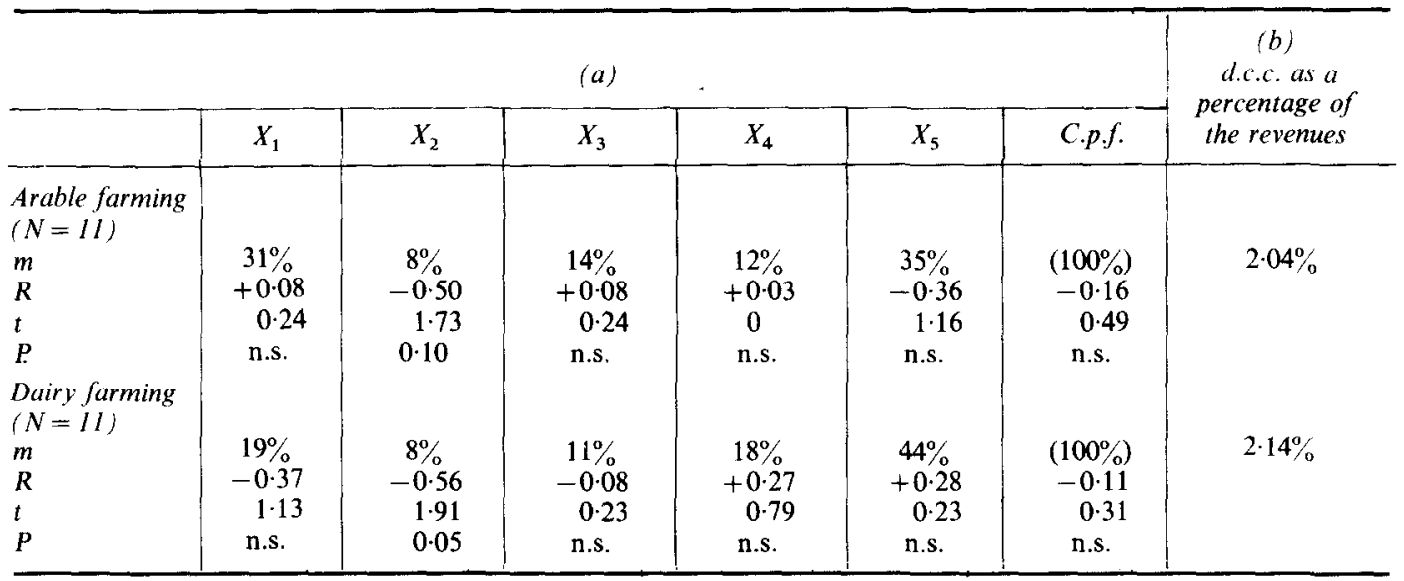

$N$ : number of farms (test sample)

$m$ : estimated test sample average

$R$ : correlation coefficient

$t$ : value of $t$-test

$P$ : level of significance

n.s.: not significant, $P>0 \cdot 10$ 
dairy farms. Method $X_{5}$ gives already a contribution of $44 \%$ to c.p.f. on dairy farms, consequently no additional decrease of d.c.c. can be expected when its application increases. This is perhaps a consequence of the fact that an important part of d.c.c. on dairy farms is due to machinery and equipment that is already (dry) sheltered and stored (like manure mixers, manure handling machines, etc.).

Use of fats, oils, waxes and lubricants (method $X_{1}$ ) demonstrates on dairy farms no clear trend directed towards a decrease of d.c.c. The correlation is not significant for $P<0 \cdot 10$. On arable farms no connection exists at all $(t=0 \cdot 24)$. On dairy farms (where $X_{1}$ delivers only a contribution of $19 \%$ to c.p.f.) a decrease of d.c.c. seems more likely when machinery and equipment is "lubricated" more frequently and regularly immediately after use. Method $X_{1}$ already contributes $31 \%$ on agricultural farms and no further decrease of d.c.c. can be expected when its application is increased.

These results give some support to the following conclusion. When a specific method of corrosion protection on a farm contributes only little to the overall applied of corrosion protection, then increased use of the method leads directly to a decrease of the direct corrosion costs.

This conclusion is, of course, also valid in reverse. Increased use of an often applied protection method (with a great contribution to the overall applied corrosion protection) causes no measurable decrease of the direct corrosion costs.

\subsection{Relation between c.p.f. and the corrosion condition of machinery}

The respective corrosion conditions are described in Appendix A, but can be summarized here as: c.c. $0=$ no corrosion problems; c.c. $1=$ superficial corrosion damage; c.c. $2=$ slight corrosion damage; c.c. $3=$ considerable corrosion damage; c.c. $4=$ very large corrosion damage.

On 22 farms in this investigation, ${ }^{2} 568$ machines were classified and arranged according to these respective corrosion conditions. A summary of the distribution is given in Table 4 .

Considering the results in Table 4 gives rise to the following remarks. More than half of the machines are ranked under corrosion condition 0 or $1(63 \%)$ and consequently have no serious corrosion problems. Only $14 \%$ of the machines are classified under c.c. 3 or c.c. 4 ; so just a small number of machines have considerable or very large corrosion damage. The number of machines on dairy farms with almost no corrosion problems (c.c. 0 and c.c.1: $51 \%$ ) is considerably smaller than on arable farms (c.c. 0 and c.c.1: $73 \%$ ). The relative number of machines with considerable or very large corrosion damage (c.c. 3 and c.c.4) is nearly twice as large on dairy farms $(18 \%)$ as on arable farms $(10 \%)$. Only $37 \%$ of the total number of machines (568) may lead to corrosion problems that can result in economic losses.

Table 4

Number of machines per corrosion condition in the arable and dairy farming activities

\begin{tabular}{l|c|c|c|c|c|c}
\hline \multirow{2}{*}{$\begin{array}{c}\text { Farming } \\
\text { activity }\end{array}$} & \multicolumn{6}{c}{ Corrosion condition c.c. } \\
\hline Arable & 0 & $l$ & 2 & 3 & 4 & $0-4$ \\
\hline (11 farms) & 81 & 145 & 51 & 23 & 4 & 304 \\
Dairy & $(26 \%)$ & $(47 \%)$ & $(17 \%)$ & $(8 \%)$ & $(2 \%)$ & $(100 \%)$ \\
(11 farms) & 46 & 90 & 81 & 42 & 5 & 264 \\
Both & $(17 \%)$ & $(34 \%)$ & $(31 \%)$ & $(16 \%)$ & $(2 \%)$ & $(100 \%)$ \\
$(22$ farms) & $(27 \%)$ & 235 & 132 & 65 & 9 & 568 \\
& $(22 \%)$ & $(41 \%)$ & $(23 \%)$ & $(12 \%)$ & $(2 \%)$ & $(100 \%)$ \\
\hline
\end{tabular}


Table 5

Correlation of c.p.f. and the relative number (\%) of machines per corrosion condition on farms

\begin{tabular}{|c|c|c|c|c|}
\hline & \multirow[b]{2}{*}{ c.p.f. } & \multicolumn{3}{|c|}{$\begin{array}{l}\text { Relative number (\%) of machines } \\
\text { per corrosion condition c.c. }\end{array}$} \\
\hline & & c.c. 0 or c.c.l & c.c. 2 & c.c. 3 or c.c. 4 \\
\hline \multicolumn{5}{|c|}{ Arable farming $(N=I 1)$} \\
\hline & $64 \cdot 7$ & $74 \%$ & $17 \%$ & $9 \%$ \\
\hline$R$ & - & +0.581 & -0.578 & -0.299 \\
\hline$t$ & - & $2 \cdot 14$ & $2 \cdot 12$ & 0.94 \\
\hline$P$ & - & $<0.05$ & $<0.05$ & n.s. \\
\hline \multicolumn{5}{|c|}{ Dairy farming $(N=11)$} \\
\hline$m$ & 51.6 & $54 \%$ & $28 \%$ & $18 \%$ \\
\hline$R$ & - & +0.493 & -0.494 & -0.124 \\
\hline$t$ & - & $1 \cdot 70$ & $1 \cdot 70$ & 0.37 \\
\hline$P$ & - & $<0 \cdot 10$ & $<0 \cdot 10$ & n.s. \\
\hline
\end{tabular}

It seems acceptable to use as a working hypothesis a positive correlation between c.p.f. and the number of machines with c.c. 0 and c.c.1 (no corrosion to superficial corrosion damage). Likewise, it is probable that a negative connection would be found between c.p.f. and corrosion conditions c.c. 2 , c.c. 3 and c.c. 4 (slight to very large corrosion damage).

Table 5 shows the test results of these assumptions for the arable and dairy farming activities. The data give rise to three remarks: a significant correlation is deduced between an increase of c.p.f. and a rise of the number of machines with c.c. 0 or c.c. 1 ; increase of c.p.f. is significantly connected with a decrease of the number of machines with condition c.c. 2 ; no clear trend is found in the relation between an increase of c.p.f. and a fall of the number of machines with c.c. 3 or c.c. 4 .

In more detail these results can be considered as follows. Increased corrosion protection leads to a shift of machines with c.c. $=2$ to machines with c.c. $=0$ or 1 . So, slight corrosion damage of machines is reduced to superficial or no corrosion damage due to improved corrosion prevention. However, increased corrosion protection does not influence the number of machines with considerable or very large corrosion damage. A possible explanation is that the improvement of the use of the corrosion protection methods included in the c.p.f. does not significantly affect reduction of large corrosion damage. This damage might predominantly occur with relatively old machinery, while farmers might look after relatively new machines better (which will probably be the machines with no to slight corrosion problems). However, the age of the machines was not included in the investigation; so this effect could not be taken into account.

Consequently the following conclusion seems correct. Corrosion prevention and control on farms may have a demonstrable effect on the corrosion condition of machinery, however, other variables could also affect the c.c., such as the age of the machines. In further research it is important to consider also this kind of variable.

\subsection{Relation between c.c. and separate prevention methods}

C.p.f. can also be used for the analysis of the contribution of separate methods of corrosion protection to an improvement of the condition of machines. The correlation between one method (e.g. $X_{5}$ ) and the number of machines per corrosion condition can be analysed. An example of this is shown in Table 6.

The results in Table 6 indicate that more frequent "dry storage" (method $X_{5}$ ) of machines leads to an improvement of the corrosion condition on arable farms. The correlation is 
Table 6

Correlation of (a) the contribution of corrosion protection method $X_{5}$ (in per cent of c.p.f.), and (b) the relative number (\%) of machines per corrosion condition on arable farms $(N=11)$

\begin{tabular}{lc|c|c|c}
\hline \multicolumn{3}{c|}{$(b)$} & \\
& \multicolumn{3}{c|}{$c . c}$. \\
& c.c.0 and c.c.l & $c . c .2$ & c.c.3 and c.c.4 & (a) \\
\hline$m$ & $74 \%$ & $17 \%$ & $9 \%$ & $35 \%$ \\
$R$ & +0.65 & -0.32 & -0.67 & \\
$t$ & 2.57 & 1.01 & 2.71 & \\
$P$ & $<0.025$ & n.s. & $<0.025$ & \\
\hline
\end{tabular}

significant for c.c. 0 and c.c. 1 , and for c.c. 3 and c.c.4. The correlation does not exist on dairy farms for $P<0 \cdot 10$. This is probably also a consequence of the previously mentioned circumstance that on dairy farms, machines which corrode rapidly, are already "stored dry" (like manure handling machines). The correlation of method $X_{5}$ with c.c. in Table 6 seems to be at variance with the lack of correlation with corrosion costs on arable farms found in Table 3. However, method $X_{5}$ already contributes $35 \%$ to the overall applied corrosion protection on arable farms. Further, in section 5.2 it has been argued that increased use of an often applied protection method (like method $X_{5}$ ) causes no measurable decrease of the direct corrosion costs, while increased use of a little applied method (like $X_{2}$ ) leads to a significant decrease of costs. Consequently, increased use of method $X_{5}$ leads significantly to more machines with less corrosion damage, but this effect is too small to cause a significant cost decrease.

So in this situation the measuring instruments c.p.f. and c.c. show to be fit for use in analysing the application of corrosion protection methods in arable farming.

\subsection{Use of c.p.f. in determining cost savings}

In previous sections relations were determined between, on the one hand, the c.p.f. or contributions of separate protection methods to c.p.f. and, on the other hand, the direct corrosion costs. The correlations showed no significance in a number of cases which is partly due to the small test sample $(N \leqslant 11)$.

But it is also caused by the circumstance that the same magnitude of the direct corrosion costs on different farms can be brought about by different combinations and contributions of separate applied corrosion protection methods, resulting in the same magnitude of c.p.f. on the different farms. This confuses the correlation analysis causing weakened significant relations - or even only trends-which has to be avoided in order to form a clear picture of the impact of several protection methods to the corrosion costs on farms.

Therefore, in this section the direct corrosion costs are compared on farms with c.p.f. higher or lower than the average c.p.f. of the whole population. Two groups of farms per farming activity are compared: those with relatively much corrosion protection and those with considerably less prevention and control. This approach will increase understanding of the development of the corrosion costs in relation to the extent of applied corrosion protection, and enable the establishment of possible net corrosion cost savings. The difference between the corrosion costs in both groups gives an estimate of the possible cost saving, which can be expressed as a percentage of the average or minimum direct corrosion costs per farm. Table 7 gives a summary of d.c.c. in two groups of farms per farming activity: farms with little and much corrosion protection. First of all it is clear that the average c.p.f. on arable farms is $13.1 \%$ smaller than on dairy farms. This average 
Table 7

Average direct corrosion costs per year on farms with c.p.f. higher and lower than the average c.p.f.

\begin{tabular}{|c|c|c|c|c|}
\hline \multirow[b]{2}{*}{ Item } & \multicolumn{2}{|c|}{ Arable farming } & \multicolumn{2}{|c|}{ Dairy farming } \\
\hline & c.p.f. $>64 \cdot 7$ & $c . p . f .<64.7$ & c.p.f. $=51 \cdot 6$ & c.p. $f<s 1.6$ \\
\hline Number of farms & 7 & 4 & 4 & 6 \\
\hline Average c.p.f. & \multicolumn{2}{|c|}{$64 \cdot 7$} & \multicolumn{2}{|c|}{$51 \cdot 6$} \\
\hline Average c.p.f. per group & $77 \cdot 0$ & $43 \cdot 2$ & $63 \cdot 0$ & $42 \cdot 3$ \\
\hline \multicolumn{5}{|l|}{ Direct corrosion costs per year } \\
\hline fl. hectare & 177 & 323 & 209 & 271 \\
\hline$\%$ of revenues & $1 \cdot 69$ & $2 \cdot 61$ & $1 \cdot 77$ & $2 \cdot 14$ \\
\hline $\begin{array}{l}\% \text { of total investment } \\
\text { (without land area) }\end{array}$ & 1.52 & $2 \cdot 70$ & $1 \cdot 12$ & 1.22 \\
\hline n./tonne milk & - & - & $13 \cdot 6$ & $17 \cdot 3$ \\
\hline fl. cow & - & - & 83 & 108 \\
\hline fi./farm & 4809 & 7294 & 6965 & 9464 \\
\hline
\end{tabular}

difference is significant for a $P=0.005$ significance level with an estimated interval $\Delta=6.5 \%$. In Table 8 some relevant statistical information is given about the significance of the differences given in Table 7 between the high and low c.p.f. farms.

With the figures in Table 7 net saving percentages are calculated for each number-see Table 9. An example is given below for the dairy farming industry (with d.c.c./ha):

$$
\begin{aligned}
\text { saving percentage } & =\frac{\text { d.c.c. } / \text { ha }(\text { c.p.f. }<51 \cdot 6)-\text { d.c.c. } / \text { ha }(\text { c.p.f. }>51 \cdot 6)}{\text { d.c.c. } / \text { ha }(\text { c.p.f. }<51 \cdot 6)} \\
& =\frac{271-209}{271} \times 100 \%=23 \% .
\end{aligned}
$$

From the results of Table 8 it can be seen that a clear difference exists between the figures of the arable and dairy farms. The average difference between c.p.f. on low and high c.p.f. farms is $-33.8 \%$ on arable farms and $-20.0 \%$ on dairy farms. These differences are

Table 8

\begin{tabular}{|c|c|c|c|c|c|c|c|}
\hline \multirow[b]{2}{*}{ Item } & \multicolumn{3}{|c|}{ Arable farms } & \multicolumn{4}{|c|}{ Dairy farms } \\
\hline & $M_{v}$ & $\Delta$ & $P$ & $M_{v}$ & $\Delta$ & $P$ & \\
\hline C.p.f. $(\%)$ & -33.8 & $8 \cdot 6$ & 0.01 & $-20 \cdot 0$ & $7 \cdot 7$ & 0.01 & \\
\hline $\begin{array}{l}\text { Direct corrosion costs per year } \\
\text { f./hectare } \\
\% \text { of revenues } \\
\% \text { of total investment } \\
\text { (without land area) } \\
\text { f. /tonne milk } \\
\text { fl. } / \text { cow } \\
\text { fl. } / \mathrm{farm}\end{array}$ & $\begin{array}{c}146 \\
0 \cdot 92 \\
\\
1 \cdot 18 \\
- \\
- \\
2488\end{array}$ & $\begin{array}{c}73 \\
0.63 \\
0 \cdot 66 \\
- \\
- \\
1859\end{array}$ & $\begin{array}{l}0.01 \\
0.01 \\
0.01 \\
- \\
- \\
0.01\end{array}$ & $\begin{array}{c}62 \\
0 \cdot 37 \\
\\
0 \cdot 10 \\
3 \cdot 7 \\
24 \cdot 7 \\
2499\end{array}$ & $\begin{array}{c}52 \\
0 \cdot 35 \\
- \\
3 \cdot 6 \\
24 \cdot 1 \\
3046\end{array}$ & $\begin{array}{r}0.20 \\
0.20 \\
\\
>0.20 \\
0.10 \\
0.10 \\
>0.20 \\
\end{array}$ & $\begin{array}{l}\text { (n.s.) } \\
\text { (n.s.) } \\
\text { (n.s.) } \\
\text { (n.s.) }\end{array}$ \\
\hline
\end{tabular}

Statistical information about the significance of the differences between high and low c.p.f. farms

n.s.: not significant: $P>0 \cdot 10$

$\Delta$ : estimated interval

$M_{v}$ : average difference between low and high c.p.f. farms

$P$ : significance level 
Table 9

Cost saving per year in per cent of the direct corrosion costs per year on farms with relatively little corrosion protection (low c.p.f.)

\begin{tabular}{l|c|c}
\hline \multicolumn{1}{c|}{ Item } & Arable farming & Dairy farming \\
\hline Direct corrosion costs & & \\
fl. $/$ hectare & $45 \%$ & $23 \%$ \\
$\%$ of revenues & $35 \%$ & $17 \%$ \\
$\%$ of investment & $44 \%$ & $8 \%$ \\
fl. $/$ tonne milk & - & $21 \%$ \\
fl. cow & - & $23 \%$ \\
fl. farm & $34 \%$ & $25 \%$ \\
f./farm & fl. 2500 & fl. 2300 \\
\hline
\end{tabular}

significant for a $P=0.01$ significance level. The differences between the various cost numbers on arable farms are all significant for $P=0.01$, that is, the average difference between the direct corrosion costs per farm is $M_{\mathrm{v}}=2488 \mathrm{fl}$./year with an estimated interval $\Delta=1859 \mathrm{fl}$./year for $P=0.01$. Because the difference between the high c.p.f. and low c.p.f. is a measure of the extent of difference in applied corrosion protection on the farms with much and little prevention and control, it is clear that significant corrosion cost savings can be realized on arable farms by improving the application of known prevention and control schemes. No significant correlations were found between the direct corrosion costs on high and low c.p.f. dairy farms. Only the d.c.c. per tonne milk and the d.c.c. per cow are weakly significant with $P=0 \cdot 10$. The d.c.c. per farm $\left(M_{\mathrm{v}}=2499 \mathrm{fl} . / \mathrm{a}\right)$ is not significant at all $(P>0 \cdot 20)$. Consequently, on dairy farms much and little corrosion prevention do not result in clearly significant differences in the corrosion costs. The results in Table 9 show that, according to the figures in Table 8, significant cost savings can be made on low c.p.f. arable farms $(34 \%$ of the direct corrosion costs), while only weakly significant cost savings on low c.p.f. dairy farms can be made [expressed as a percentage of the d.c.c. per tonne milk $(21 \%)$ or per cow $(23 \%)]$.

This result appears to be in conflict with the relative effects of corrosion prevention on costs in arable and dairy farms as is given in Table 2 for the costs of maintenance, repairs and small materials. However, these particular costs may be confusing because on dairy farms nearly all the costs of maintenance and repairs will be included in this number (because much repair work is carried out off-farm and is therefore included in this research), while much maintenance and repair work on arable farms is carried out on-farm (and therefore not completely covered by this research as is argued in Section 4). Consequently, this cost may be underestimated on arable farms, leading to the result in Table 2. Therefore this cost is not included in the analysis in Tables 8 and 9.

\section{Conclusions}

The main findings of this investigation can be summarized as follows.

The direct corrosion costs on 22 arable and dairy farms have been estimated to amount to two thirds of the total corrosion costs in both farming activities. The direct costs amount to about $2 \%$ of the total revenues in both industries.

In general, the correlations between the c.p.f. and the d.c.c. are very weak in both farming activities.

Dry storage of machinery and equipment give in both farming activities the greatest contributions to the overall applied corrosion protection: the contribution to c.p.f. on dairy farms is $44 \%$ and on arable farms $35 \%$. 
Painting of rusty parts and surfaces delivers in both farming industries the smallest contribution to c.p.f. (8\%). Since painting as a corrosion protection method is consequently still used to only a small extent in comparison with other methods, extension of use of the method may lead to reduction of corrosion costs. This is confirmed by correlations between the extent of use of this corrosion protection method on farms and the direct corrosion costs.

It can be said in general that increased use of a seldom applied corrosion protection method leads directly to a decrease of the direct corrosion costs. Increased use of an often applied method causes no measurable decrease of the direct corrosion costs.

The percentage of machines on dairy farms with almost no corrosion problems $(51 \%)$ is considerably smaller than on arable farms $(73 \%)$. The relative number of machines with considerable or very large corrosion damage is nearly twice as large on dairy farms $(18 \%)$ as on arable farms $(10 \%)$. Correlations between the c.p.f. and the relative number of machines per corrosion condition confirm that corrosion protection on arable and dairy farms increases the number of machines with no or only slight corrosion problems.

A significant correlation is observed on arable farms between more frequent "dry storage" of machinery and improvement of the corrosion condition. However, the correlation with the direct corrosion costs is not significant. On dairy farms no connections were found at all. When the average direct corrosion costs on farms with c.p.f. higher and lower than the average c.p.f. are compared it is estimated that cost savings per year of about fl. 2500 per farm can be reached in arable farming. No significant correlations are found between the direct corrosion costs on high and low c.p.f. dairy farms. These comparisons lead to the conclusion that corrosion cost savings, especially in arable farming, are realized by improving the application of known prevention and control schemes.

In this research a combination of corrosion protection methods is proposed that may lead to a decrease of corrosion costs. These protection methods can be fitted into the working and production scheme of the farmer in a meaningful way. They are summarized as follows:

(1) cleaning and washing of machinery and equipment with a high pressure jet (especially of corrosion sensitive spots and parts) immediately after use to remove aggressive deposits;

(2) use of oils, lubricants and sealants on metallic parts (after good drying), and spraying with oil on metallic surfaces and parts directly after use;

(3) storage of machinery and equipment in a dry environment immediately after use;

(4) painting of metal surfaces and parts (after a thorough pretreatment) when rust spots and general rusting have become visible;

(5) inspection and preventative maintenance.

\section{Acknowledgements}

This article is based on the engineering degree thesis ${ }^{2}$ of an investigation carried out in Spring 1983 into the technical, economic and organizational aspects of corrosion and prevention in farming industries in The Netherlands. The support by the Dutch Corrosion Centre (NCC) and the Institute of Agricultural Engineering (IMAG) is gratefully acknowledged.

\section{References}

1 Schouten, J. C.; Gellings, P. J. Quantitative measures of corrosion and prevention: definitions and properties. British Corrosion Journal 1984, 19(4): 159-164

2 Schouten, J. C. Corrosion and corrosion protection in the farming industries. Engineering degree thesis, Twente University of Technology, Enschede, The Netherlands, 1983

3 Bishop, R. J. Corrosion prevention in agriculture. The Agricultural Engineer, Winter 1981, 103-108

4 Elliott, P.; Fowler, C. M.; Johnson, J. B.; Wood, G. C. Corrosion and materials degradation in the agricultural industry. The Agricultural Engineer, Spring 1983, 13-20 
5 Corrosion in Agriculture. Guides to Practice in Corrosion Control, No. 15, Department of Industry, England, 1982

6 Jansson, I. Corrosion in Animal Buildings, Proceedings CIGR Section II Serninar, Aberdeen, 1981, pp. $275-278$

7 Corrosion in Agriculture. Conference Proceedings, CFIT, University of Nottingham, Department of Industry, England, 1977

8 Gellings, P. J. Introduction to Corrosion Prevention and Control. Delft University Press, 1985

9 Henthorne, M. Fundaments of Corrosion, Refresher Series, Parts 1-12. Chemical Engineer $1971-1972$

10 Economic Effects of Metallic Corrosion in The United States. A report to the Congress by the National Bureau of Standards, Part I, Washington, May 1978

1 Schouten, J. C. Millions damagc annually duc to corrosion in the farming industries. Landbouwmechanisatie 1983, 34(5): 551-553

\section{Appendix A: Definitions and calculation procedures}

\section{A1. The corrosion protection factor}

The corrosion protection factor (c.p.f.) is defined ${ }^{\mathbf{1}}$ as a measure of the way and the extent that corrosion prevention and control are carried out. C.p.f. is given on a scale from 0 to $100 \%: 0 \%=$ corrosion protection is nil; $100 \%=$ corrosion protection is optimum.

The c.p.f. is determined on the basis of the difference in effectiveness of specific corrosion protection methods. The calculation of c.p.f. proceeds from two main questions according to these definitions. The questions are:

(a) which corrosion protection methods or forms of maintenance are applied?

(b) how frequently are they used?

The following procedure is applied for the calculation of c.p.f.;

(1) All corrosion prevention and control methods that can possibly be applied in a certain case are summarized. These methods are covered by the general term corrosion protection methods. Possible methods are: painting; metallic coating; cathodic protection; use of corrosion resistant materials; corrosion allowance; use of grease, waxes, lubricants, etc.; regular cleaning and washing of machinery and equipment. The various methods are indicated with the variable $X_{i}$.

(2) An effectiveness order is defined, using published data and experience. Every method is linked with an effectiveness factor, $x_{i}$, which denotes the relative effectiveness of the specific method compared with the other methods.

(3) For each method the extent of application is defined by the frequency of use. This frequency of use, $f_{i}$, is obtained using experience and published data, by attaching quantitative values $\left(c_{i j}\right)$ to a qualitative description of the extent of use of the respective corrosion protection methods $X_{i}$.

The value of the frequency of use of method $X_{i}$ is $f_{i}=c_{i j}$. In $c_{i j}, j$ corresponds with exactly one possible qualitative description of the extent of use of method $X_{i}$. The total number of descriptions, $m$, is equal for all methods $X_{i}$; so $1 \leqslant j \leqslant m$.

(4) The c.p.f. is then expressed as a percentage $(\%)$.

In such a way the c.p.f. can be calculated with the following equation:

$$
\begin{aligned}
\text { c.p.f. } & =\left[\left(\sum_{i=1}^{n} c_{i j} \times x_{i}\right) /\left(\sum_{i=1}^{n} c_{i m} \times x_{i}\right)\right] \times 100 \% \\
& =\left[\left(\sum_{i=1}^{n} f_{i} \times x_{i}\right) /\left(\sum_{i=1}^{n} c_{i m} \times x_{i}\right)\right] \times 100 \%
\end{aligned}
$$


in which $j$ is $1 \leqslant j \leqslant m$ for each method $x_{i} ; n$ is the number of applied corrosion protection methods.

An example of the calculation of the c.p.f. on a farm will now be given.

(1) The following corrosion protection methods are considered:

$X_{1}$ : use of fats, oils, waxes and lubricants on metal parts; spraying with gasoline on corrosion sensitive spots and parts immediately after use;

$X_{2}$ : painting of metal parts, after a thorough pretreatment of the surface, when the metal is affected by corrosion (rust formation has become visible);

$X_{3}$ : cleaning and washing of machinery and equipment immediately after use;

$X_{4}$ : cleaning of corrosion sensitive spots and parts with a high pressure jet immediately after use;

$X_{5}$ : storing of machinery and equipment in a dry environment (barn, shed or depository).

(2) The following values are used for the effectiveness factors, $x_{i}$, per corrosion protection method (partly based on data given elsewhere $1,2,4,5$ ):

\begin{tabular}{c|c|c|c}
\hline$X_{i}$ & $x_{i}$ & $X_{i}$ & $x_{i}$ \\
\hline$X_{1}$ & 2 & $X_{4}$ & 1 \\
$X_{2}$ & 1 & $X_{5}$ & 3 \\
$X_{3}$ & 1 & & \\
\hline
\end{tabular}

(3) The qualitative descriptions, $j$, of the extent of use of method $X_{i}$, with the matching quantitative points of use, $c_{i j}$, are indicated as:

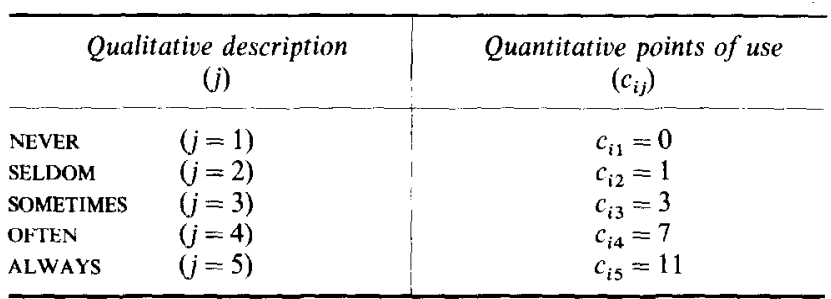

Consider a specific farm where method $X_{1}$ is used sometimes, method $X_{2}$ is used seldom, method $X_{3}$ is used often, method $X_{4}$ is used often and method $X_{5}$ is used sometimes. Then the c.p.f. becomes:

$$
\begin{aligned}
\text { c.p.f. } & =\left[\left(\sum_{i=1}^{5} f_{i} \times x_{i}\right) /\left(\sum_{i=1}^{5} c_{i 5} \times x_{i}\right)\right] \times 100 \% \\
& =[30 / 88] \times 100 \%=34.1 \% .
\end{aligned}
$$

The contribution, c.p.f. (A), of one specific method $X_{i}=X_{\mathrm{A}}$ to the overall applied corrosion protection on the farm can be expressed as a percentage of the c.p.f. as:

with $1 \leqslant A \leqslant n$.

$$
\text { c.p.f. }(\mathrm{A})=\left[\left(f_{\mathrm{A}} \times x_{\mathrm{A}}\right) /\left(\sum_{i=1}^{n} f_{i} \times x_{i}\right)\right] \times 100 \%
$$

Consequently, the contribution of method $X_{3}$ (cleaning and washing) to c.p.f. in this specific example amounts to:

$$
\begin{aligned}
\text { c.p.f. (3) } & =\left[\left(f_{3} \times x_{3}\right) /\left(\sum_{i=1}^{5} f_{i} \times x_{i}\right)\right] \times 100 \% \\
& =[(7 \times 1) / 30] \times 100 \%=23 \cdot 3 \%
\end{aligned}
$$


So cleaning and washing of machinery and equipment immediately after use gives in this example a contribution of nearly a quarter to the total applied corrosion protection on this farm.

\section{A2. The corrosion condition}

The corrosion condition (c.c.) is defined ${ }^{\mathbf{1}}$ as the technical corrosion situation of a machine and/or its parts. The c.c. is established using a simple classification schedule, similar to that given by Elliott et al.:4

\begin{tabular}{|c|c|}
\hline Corrosion condition (c.c.) & Description \\
\hline c.c. 0 & No corrosion problems; no rust \\
\hline c.c. 1 & $\begin{array}{l}\text { Superficial corrosion damage; release of paint; peeling off; rusty bolts, nets } \\
\text { and screws; slight rusting; small rusty spots }\end{array}$ \\
\hline c.c. 2 & $\begin{array}{l}\text { Slight corrosion damage; pits in iron and steel; rusty spots and parts; } \\
\text { stronger rusting }\end{array}$ \\
\hline c.c. 3 & $\begin{array}{l}\text { Considerable corrosion damage; thinning of material; bolts, etc. get stuck } \\
\text { and rusted; holes in material and constructions; rusting through of parts } \\
\text { and surfaces }\end{array}$ \\
\hline c.c. 4 & $\begin{array}{l}\text { Very large corrosion damage; broken parts; risk of breaking off of pieces of } \\
\text { material; jamming of machines; parts getting stuck; collapse of structures; } \\
\text { necessity of replacement }\end{array}$ \\
\hline
\end{tabular}

The assessment of the c.c. is made after visual observation of the machine and according to information given by the farmer. 